\title{
Choices without reasons: citizens' juries and policy evaluation
}

David Price University of Northumbria, Nezwcastle upon Tyne

\begin{abstract}
Citizens' juries are commended as a new technique for democratising health service reviews. Their usefulness is said to derive from a reliance on citizens' rational deliberation rather than on the immediate preferences of the consumer. The author questions the assertion of critical detachment and asks whether juries do in fact employ reason as a means of resolving fundamental disagreements about service provision. He shows that juries promote not so much a critically detached point of view as a particular evaluative framework suited to the bureaucratic idiom of social welfare maximisation. Reports of jury practice reveal a tendency among juries to suppress by non-rational means the everyday moral language of health care evaluation and substitute for it a system of thought in which it can be deemed permissible to deny treatment to sick people. The author concludes that juries are chiefly concerned with non-rational persuasion and because of this they are morally and democratically irrelevant. Furies are no substitute for voting when it comes to protecting the public from zealous minorities.

(Fournal of Medical Ethics 2000;26:272-276)
\end{abstract}

Keywords: Citizens' juries; deliberative democray; health care rationing; public consultation; social welfare; public choice

\section{Introduction}

At the last count, about a third of health authorities in England and Wales were reporting financial difficulties. ${ }^{1}$ Many are using acute service reviews as means of rationalising local services in order to get out of deficit. But authorities must consult with the public about proposals involving substantial changes to their services and the need to win public support for contentious cost-saving plans like hospital closure has contributed to a spirit of innovation in methods of consultation. The techniques of deliberative democracy have been offered as one way forward. Deliberative democracy can mean a number of things but it is generally understood to be a device for broadening the social base of policy evaluation. If more people are involved in the selection of the criteria used to evaluate policy options, then the process of selection is deemed more democratic, defensible, or protective of the public good than it would otherwise be. ${ }^{2}$ The use of deliberative techniques is intended to absolve health authorities from charges of being dictatorial without requiring them to go the whole hog and conduct a poll.
In this paper I examine one particular form of deliberative democracy, citizens' juries, and ask how the process of value selection works. It is a central question for supporters of the democratic credentials of deliberative techniques whose model relies on the claim that people can reach agreement about values as a result of debate and discussion. This is an important claim with far reaching implications. I will argue, however, that the basis of agreement secured by juries is not the basis generally claimed for them and that consequently juries do not fulfil the democratic role they have been allotted.

\section{The issue}

In 1996, Cambridge and Huntingdonshire Health Authority convened a citizens' jury to "address" the question of rationing health care. ${ }^{34}$ For four days the jury heard expert witnesses, read written evidence, deliberated and then changed its mind about the celebrated Child B case in which a young girl had apparently been refused a second bone marrow transplant by the authority. On day one, most jurors were "sympathetic" to Child B. But by the final day, they decided that the criterion of "effectiveness" (the probability of a good outcome) was more important than "risk-taking", that this was a correct description under which to put the Child B decision, and that on the strength of it the authority had been right to refuse treatment. It was a striking result. In four days, the jury had apparently resolved their moral differences with the authority. Given that contemporary moral philosophy suffers from an endemic inability to agree, this mechanism for consensus deserves our attention. Do citizens' juries offer a way of rationally resolving disagreement and should they be used more widely?

\section{What are juries and why are they advocated?}

Citizens' juries are experiments in the involvement of "citizens" in policy-making. Since 1994, they have been widely canvassed in the United Kingdom by the Institute for Public Policy Research (IPPR), which has published a series of jury reports, and by the King's Fund which believes they have special relevance for health authorities trying to justify "difficult decisions". ${ }^{35}$ Juries typically consist of a random, stratified sample of "ordinary citizens" selected to represent the wider society. ${ }^{6}$ They range in size, the IPPR preference being for between 12 and 16 jurors, and may meet for several days. Under the guidance of a moderator who should be 
independent of the organisation that commissions the jury, they "hear evidence, call witnesses and make recommendations on proposals submitted to them". They are said to "make decisions" and are "indicators of what an informed public would come to feel given time, resources and information about the relevant issues at stake". ${ }^{3}$

The terms used in these accounts deserve close attention. "Citizenship" conveys notions of democracy, rationality, moral objectivity and conceptions of the public good. Consensual decision making by citizens sounds as if it should be reasonable and disinterested, a successful application of what Baier has called "the moral point of view". ${ }^{7}$ The purpose of political arrangements which enable people to participate in the conduct of public affairs as citizens rather than as, say, customers is to arrive at judgments which are the result of responsible and disinterested critical reflection. Deliberating citizens do not just fulfil another social role; they embody a critical standard which can be applied to the attitudes or preferences associated with all social roles. Given citizens, the state has all it needs to rise above the intractable horse-trading of preference-based, normal politics. ${ }^{8}$ Political arrangements for citizens' deliberation are fundamentally concerned with reaching judgments rather than with registering attitudes and it is the citizen who supplies the evaluative and normative standards which make this possible. ${ }^{9}$ This type of participation is a non-dictatorial response to perceived inadequacies in representative democracy. ${ }^{10}$

A shift in policy emphasis has given this distinctive concept of citizenship a new relevance. For a number of years official rhetoric has favoured public involvement in decision making. But whereas the basic model of the 1980s and early 1990s was predicated on the public as consumers of a given range of services, the public is now conceived as a collection of citizens who can be consulted not only about the standards of existing patterns of service delivery but also about what services should be provided. ${ }^{10} 11$ This change of focus has been marked by a new health care politics. Where "charter politics" was about the consumer wants of service users, the new politics of consultation is concerned with values in the light of which to evaluate the whole service system.

The consultative technologies which have accompanied the new politics are therefore focused on the processes of reaching a common set of values as much as on registering individual preferences.

Why should values be an issue? Service rationalisation involves fundamental changes to service norms and a shift in the boundary between individual and state responsibility. In health care, for example, the redistribution of general hospitals and other medical services is related not just to changes in medical practice but also to changes in the expectations which the public has of the National Health Service (NHS) and in beliefs about the expectations they ought to have. If such reforms are going to be accepted, people have to be persuaded that what was right in the past is no longer right. In other words, people have to accept a new evaluative structure.

This has been clearly articulated by Philip Hunt, a former chairman of the National Association of Health Trusts: "If an inherently conservative public is not to prevent the NHS from making the most of [scientific and technological] advances, effective ways have to be found to bring the public into discussions about how the service might respond to them". ${ }^{12}$ Unfortunately, he goes on, whilst "advances in health care point to fewer, more intensively used hospitals, local communities do not want to see themselves as local communities without a hospital in their backyard".

Lord Hunt here draws a crucial distinction between the public's "simple" or unreflective preferences and the preferences which it will or ought to have were it to deliberate. He believes that the public good is not promoted by relying on people's simple, immediate preferences because these are both self-serving and sentimental. On this view, the role of consultation is to modify and filter attitudes. But what is being transformed and how?

\section{Transforming evaluative structures}

In the standard model of liberal democratic decision making, individuals follow their own ideas about what counts as a good reason for a decision. A new evaluative structure which commands agreement or consensus must somehow go beyond this. The new values have to appeal, have to be preferred, as sources of reasons for opting for one policy instead of another.

The key idea here is the distinction drawn between personal preferences and what it would be right to do. The practical requirements of deliberation involve the claim that a decision can be validated as a right decision so that it may be said that people ought to prefer it. In other words, successful deliberation should allow us to say that people ought to be motivated to support a particular policy because there are good reasons for it and these reasons arise from an act of evaluation.

In my opening example I referred to the case of Child B and a jury's final assessment that "effectiveness" was the correct evaluative criterion. What this example shows is that a moral disagreement with the health authority was resolved as soon as the jury adopted the same criterion for assessing the decision. Disagreements might have remained, of course, but these could only have been conceptual and factual, relating either to the definition of effectiveness or to its measurement. This jury's deliberations must therefore have involved some means of persuading people of the validity of the new criterion.

But we can say more than this. The evaluative criterion the jury adopted was of a type particularly suited to the idioms of bureaucratic decision making. The jury had come to understand that the appropriate criterion of value involved measures of social welfare. Their judgment about the Child B decision implied that they had calculated that greater social benefit would follow were health care 
resources directed to effective clinical interventions. Their moral objections to the decision dissolved once they learned that the implications of the decision had to be understood in terms of their consequences for social welfare.

However, moral philosophy offers no knockdown arguments for choosing one set of evaluative criteria rather than another. Social welfare is no more defensible than any other criterion. There is nothing obviously right about it. In fact, for reasons which I shall come to later, it is in many respects an inappropriate tool for evaluating personal health care. Even the principle of a critically detached point of view, the moral point of view, is questionable. But if debates about values cannot be resolved by rational means then deliberation is not about disinterested reflection on reason and justice but about the arts of persuasion and attitude change. And if this is true, then the fact that twelve or sixteen people have been persuaded to change their minds has no wider significance.

Citizens' juries are interesting because of the ways in which they promote a distinctive mora stance without at first appearing to do so. In the remaining sections of this paper I review jury theory and practice in order to show how this is done.

\section{How the jury literature accounts for citizens}

I argued above that citizenship relies fundamentally on the belief that there is a critically detached point of view. How has the jury literature described and accounted for this standpoint?

Coote and Lenaghan suggest that citizenship is the "perspective" of "broader and longer-term interest" occupied by "voters, taxpayers and members of the community...". ${ }^{3}$ Elsewhere, citizens are said to be deeply committed to "their families, neighbours and fellow citizens" but without vested interests and neither primarily service users nor patients. ${ }^{3}$ Not surprisingly, for Coote and Lenaghan, the chief problem is locating citizens. Citizens, they tell us, "either remain invisible, silent and excluded, or ... turn, if provoked, to oppositional politics". ${ }^{3}$ Lenaghan, too, sees citizenship as essentially a problem of selection: "To retain impartiality it may also be necessary to vet jurors to ensure that none has a vested interest". ${ }^{7}$ For Kuper, on the other hand, jury members are "ordinary citizens" who can be encouraged to think of the public interest in "the jury situation". ${ }^{13}$ Coote and Mattinson also offer "dialogue" as a route to citizenship. ${ }^{4}$ In Birmingham, a jury-like panel of prestigious local figures was convened to undertake a "critical appraisal" of health authority plans. Its members were "individuals who live and work in the city" and who did not have a "fierce commitment" to individual institutions but an overriding loyalty to "the NHS in Birmingham". ${ }^{14}$ The capacity for critical detachment was here a function of the social status of the panel's members and their loyalty to their home town.

The contradictions in these accounts are revealing. A citizen is impartial, lacking a vested interest, or neutral, and yet also a tax-payer and member of the community, committed to family, friends, his or her city, or even the NHS. Citizens are at once disinterested and committed. They contemplate broader interests and yet are motivated by relatively narrow ones. They take the longer view and yet may also have to be educated into it.

These attempts to describe the moral point of view are eclectic and the language essentially rhetorical. It is impossible to derive from them a clear account of the type of person who is capable of responsible moral criticism although it is pretty clear whom they would exclude from that category. The accounts cast doubt on the legitimacy of policy critics such as health care professionals and local hospital users, both of whom have "vested interests", and the new virtue of "ordinariness" serves to depreciate technical mastery and professional competence. If managers were seeking total control over health care resources, this exclusionary approach would help to promote their own peculiar brand of expertise.

\section{The use of 'maximising' questions}

The way questions are framed will obviously influence value selection. If those who commission juries also pose the questions then the jury process is open to the charge that its agenda has been controlled. To overcome this, independent jury organisers have given accounts of the separation between commissioning and question design. However, these precautions overlook a potentially more serious bias which is the form which questions take, not merely the substantive area of discussion. I suggest that form acts in an exclusionary way because the implicitly welfare maximising terms of most reported jury questions serve to suppress nonwelfare maximising language.

Clearly jury questions have favoured social welfarist considerations. In Cambridgeshire, a citizens' jury was asked to address the questions: should the public be involved in making decisions about health care priorities, and what criteria should be used to decide about health decisions? In Kensington, Chelsea and Westminster, the question was: what can be done to improve the quality of life for people with severe and enduring mental illness, carers and their neighbours. In Walsall, jurors had to assess four alternative models for improving palliative care. In Luton the jury was asked: how should citizens pay for health services in the future. ${ }^{34}$

Each of these questions carries an implicit moral emphasis in which the discourse is likely to be at least consequentialist and probably welfare-maximising. Each lends itself to formulations of the type: what state of affairs will ensue from this decision and will society be better or worse off as a result.

Jurors evidently had some difficulty with the approach. Several jurors had to be reassured that they were competent or entitled to make such judgments; some wanted to leave decisions to the doctors. I suggest that one reason for this diffidence was the language of welfare maximisation. As a matter of fact, our everyday evaluative language, at least so far as personal health care is concerned, is unlikely 
to be wholly or even mainly consequentialist. When we talk about health care we are as likely to talk about what people do to or for us. We evaluate actions as much as consequences or states of affairs. We talk about our rights, our dignity, or our autonomy; about kindness, rudeness, or attentiveness. And even when we evaluate consequences, this is likely to be in personal rather than social welfare terms; we will say whether we have less pain or more movement.

These appreciations are evidently not the stuff of which service evaluations are made and they raise considerations which may be inimical to service reconfiguration-questions about personal conduct not resource aggregations. In evading evaluations of actions, question-framing served to suppress a commonplace evaluative language.

\section{The absence of reasons}

There is third way in which juries help to promote one particular moral or evaluative stance at the expense of others. It has to do with the type of decisions juries are said to make and the apparent lack of reasons for them.

Juries are said to take decisions but this is only true in a very limited sense. Accounts of jury transactions suggest complex discussions which seldom seem to boil down to what most people would recognise as a decision. Qualifications entered by jurors and the results of polls taken during jury proceedings are recorded and interpreted in fairly lax ways. Often jurors" "feelings" and "thoughts" are reported as if they were decisions. In some cases, even the proposition under consideration had an uncertain meaning. (For example, what does it mean to ask whether the public should be involved in health care rationing?) And by and large jury reports do not tell us why-for what reasons - the jury decided what it did. Such "decisions" are in fact indeterminate. They yield not so much recommended actions as thoughts somewhere in the background of decision making. This is not surprising when one remembers that the jury literature skates over the question of how the critical point of view is reached. All the citizens' jury offers is a framework for the justification of mora decisions, however arrived at in practice. In consequence, it offers after the fact justifications because juries do not follow a practice by which people can arrive at moral decisions nor does the jury literature provide an account of one.

The indeterminacy of jury decisions is formalised in the relationship juries have with their commissioning health authorities. Health authorities were said to be bound not by the jury "decisions" but only by a duty to provide reasons for any subsequent departure from them. But this constraint is more apparent than real: if juries made decisions which were based on reasons, then decisions would be the concluding terms of practical syllogisms and it would be illogical to accept the premises but not the conclusions (or decisions). However, jury "decisions" are not conclusions in this sense. Feelings and thoughts do not function in this way. Consequently, the basis of the constraint on the commissioning authorities is not a rational constraint but at the most a public relations one.

\section{The use of erroneous arguments}

A specific moral stance is dictated, finally, on the strength of poor or illogical argument. Quite simply, in Cambridgeshire at least, the jury was subjected to flawed reasoning as it was invited to move between case studies and general principles.

As we have seen, the Child B case was presented to the Cambridge jury as an instance of the dilemma between risk-taking and effectiveness. The purpose of deliberation was to determine which standard ought to apply both generally and in the particular case. But why should the moral issue concerning the case of Child B be put under this type of description? Did the description fully capture the complexities? After all, this was a case which had exercised national papers for weeks and ultimately reached the Court of Appeal. Could it seriously be suggested that so much controversy was expressible within the simple opposition of two abstractions and the implied balancing of an individual good against the general good? On the contrary, it was simply wrong to assume that the rights of the case were deducible from these general principles because no general theory obtains in this area and the assumption that it does is a mistake.

But even had it been possible to resolve this particular case purely on the question of an effective outcome, what followed? If the good of a child entails withholding treatment on medical grounds, what universal right (or no-right) can be logically inferred from this? The answer is, none; the procedure is illogical. The good in a particular case is not generalisable and it is an error to suppose that it can be the source of a universal principle.

There is another respect in which case studies stand in an uneasy relationship with the need for universalisable principles and public reasons. Extracting all the principles from individual medical decisions can only provide public reasons if all the particular reasons for the decision are publicly stateable. But Williams has suggested that this may not be possible. It is not just a matter of confidentiality and the nuances of personal judgment. Some reasons may not be stateable because they do not take the form of public justifications. For example, the statement: "You must do your utmost; this is a sick child", would be in Williams's account "more convincing a reason than any reason which might be advanced for its being a reason". ${ }^{15}$

As a matter of fact, the jury did not change its mind about the Child B case. It was persuaded by non-rational means to redescribe the case and overcome an initial reluctance to answer the question. It was induced to use descriptive terms which it at first found alien and adopted reluctantly. The required form of justification, one expressed in the language of social welfare, corrupted the justificatory process. Miss Anscombe described this profoundly immoral process more than forty years ago. It involves constructing systems of thought in which it becomes possible to debate whether the denial of health care 
to sick people may in some circumstances be rightnot that it is right or wrong in principle, but that there may be a principle available by reference to which virtuous people could determine whether in certain circumstances our ends justified such a course of action; that, in other words, the denial of treatment to sick people is in principle open to question and not simply an act of injustice. ${ }^{16}$

\section{Conclusion}

I have argued that citizens' jury deliberations do not involve a rational enquiry into the justification and selection of values. Juries function as mechanisms for democratising the selection of values only in the very limited sense that they expose small groups to exercises in attitude change. I have given examples from several pilot exercises in support of this claim. I have not considered the question of representativeness, that is, of juries' relationship to the wider society, because this issue is secondary to my main concerns and it has been covered elsewhere. ${ }^{17}$

If I am right, participatory democracy as practised in citizens' juries is not the unalloyed democratic innovation it is often cracked up to be. It relies much more on democratic imagery, on the ghost of the Greek polis and the American town meeting, than is perhaps comfortable. This is why debates about values, in juries and elsewhere, cleave to the slippery language of community and identity when the modern state or state bureaucracy is ill-equipped to evoke either. The public is deeply committed to the ideal of the NHS and to individual NHS establishments, but "loyalty to the NHS in Birmingham" is flimflam.

There is a tradition in participatory democracy which has tended to elevate its educative function above its rational content. Democracy so understood is about inculcating a sense of membership in a greater community. Such a democracy has the capacity to remain paternalist even as it transforms and educates. Citizens' juries, or the examples of them so far reported, stand in this tradition. They do not afford democratic protection against zealous minorities and it is not clear that they are intended to. For democratic protection we should be turning to other well-tried devices. One which springs to mind is the opportunity to vote out those who fail to persuade. When NHS policies are made at the local level, why should health authority boards be protected from this democratic sanction?

\section{Acknowledgement}

With thanks to Professor Colin Leys and two anonymous reviewers.

David Price is Research Fellow in the Social Welfare Research Unit, University of Northumbria at Newcastle, Newcastle upon Tyne.

\section{References}

1 NHSME. NHS (England) summarised accounts 1996-97. London: The Stationery Office, 1998, HC 923

2 Hylland A. The purpose and significance of social choice theory. In: Elster J, Hylland A, eds. Foundations of social choice theory. Cambridge: Cambridge University Press, 1986: 57.

3 Coote A, Lenaghan J. Citizens' juries: theory into practice. London: Institute for Public Policy Research, 1997.

4 Coote A, Mattinson D. Twelve good neighbours: the citizen as juror. London: The Fabian Society, 1997.

5 Cooper L, Coote A, Davies A, Jackson C. Voices off: tackling the democratic deficit in health. London: Institute for Public Policy Research, 1995.

6 Lenaghan J, New B, Mitchell E. Setting priorities: is there a role for citizens' juries? British Medical fournal 1996;312:1591-3.

7 Baier, K. The moral point of view. Cambridge: Cambridge University Press, 1958.

8 Barber B. Strong democracy. Berkeley: University of California Press, 1984: 211 .

9 Sunstein C. Constitutions and democracies: an epilogue. In: Elster J, Slagstad R, eds. Constitutionalism and democracy. Cambridge: Cambridge University Press: 336

10 Harrison S, Mort M. Which champion, which people? Public and user involvement: health care as a technology of legitimation. Social Policy and Administration 1998;32:60-70.

11 Milewa T, Valentine J, Calnan M. Managerialism and active citizenship in Britain's reformed health service: power and community in an era of decentralisation. Social Science and Medicine 1998;47:507-17.

12 Hunt P. Accountability in the National Health Service. Parliamentary Affairs 1995;48:297.

13 Kuper R. Deliberating waste: the Hertfordshire citizens' jury. Local Environment 1997;2:139-53.

14 Birmingham Health Authority. Simply the best: the report of the independent advisory panel on Birmingham's health care future. Birmingham: Birmingham Health Authority, 1998.

15 Williams B. Moral luck. Cambridge: Cambridge University Press, 1981: 81 .

16 Anscombe GEM.The collected philosophical papers of GEM Anscombe [vol 3]: ethics, religion and politics. Oxford: Blackwell, 1981: 144

17 Pickard S. Citizenship and consumerism in health care. Social Policy and Administration 1998;32:226-44.

\section{News and notes \\ Fifth World Congress of Bioethics}

The International Association of Bioethics has announced that the Fifth World Congress of Bioethics will take place at Imperial College, London from 21-24 September 2000

Associated organisations are: The British Association for the Advancement of Science; the British Medical Association; the European Association of Centres of Medical Ethics; the Institute of Medical Ethics; the Millenial Festival of Medicine; the Nuffield Council on Bioethics; the Royal
College of Nursing; the Royal College of Psychiatrists, Philosophy Special Interest Group; the Society for Applied Philosophy; the UK Forum for Healthcare Ethics and Law, and the World Health Organisation.

For further information please contact: Sara Hassen, 5th World Congress of Bioethics, 1 Riverside, St Anne's Road, Bristol, BS4 4ED or email: enquiries@inanyevent-uk.com or use the Congress Website at http://www.uclan.ac.uk/facs/ethics/fifthcon.htm 